\title{
Integração ensino-serviço-comunidade, metodologias ativas e Sistema Único de Saúde: percepções de estudantes de Odontologia
}

\author{
Teaching-service-community integration, \\ active methodologies and Unified Health System: \\ perceptions of Dentistry students
}

\author{
Alessandro Diogo De-Carli (1D, Adélia Delfina da Motta Silva ${ }^{1}$ (D), \\ Edilson José Zafalon ${ }^{1}$ (1), Sandra Minardi Mitre ${ }^{2}$ (1), Paulo Zárate Pereira' ${ }^{1}$ (1), \\ Rafael Aiello Bomfim ${ }^{1}$ (1), Leila Foerster Merey ${ }^{3}$ (1), Melina Raquel Theobald ${ }^{4}$ (])
}

\begin{abstract}
Resumo
Introdução: O modelo tradicional de formação em saúde hegemônico e tecnicista limita as respostas às demandas atuais do Sistema Único de Saúde (SUS). Para superar essas fragilidades, a integração ensino-serviço-comunidade (IESC) e as metodologias ativas (MAs) se apresentam como estratégias de reorientação da formação profissional. Objetivo: Este estudo analisou as percepções de estudantes de Odontologia da Universidade Federal de Mato Grosso do Sul (UFMS) acerca das práticas pedagógicas à luz das MAs e da IESC no e para o SUS. Método: Trata-se de pesquisa qualitativa, realizada entre 2012 e 2013, com 73 estudantes que estavam matriculados e cursando a disciplina de Estágio Obrigatório de Odontologia em Saúde Coletiva II (EOOSC II). O convite para participar da pesquisa foi feito após o encerramento da disciplina, quando as notas já haviam sido lançadas. Utilizou-se de um roteiro contendo questões norteadoras, que versavam sobre a opinião dos estudantes acerca: (1) da disciplina; (2) das potencialidades e fragilidades da metodologia de ensino-aprendizagem utilizada e das unidades de saúde frequentadas; e (3) da intenção de, após a formatura, trabalhar no SUS/Estratégia Saúde da Família. Após a coleta, os dados foram transcritos, e, na sequência, foi processado o discurso do sujeito coletivo (DSC). Resultados: A IESC, articulada com as MAs, propiciou aos estudantes conectar teoria e prática, integrada à realidade do SUS. Conclusão: Os participantes da pesquisa relataram a relevância da educação permanente em saúde e as dificuldades/potencialidades da utilização de MAs integradas à IESC na formação profissional, apontando o SUS como real possibilidade de trabalho ao se formarem.

Palavras-chave: formação profissional; educação em odontologia; estudantes de odontologia; metodologias ativas de ensino-aprendizagem; Sistema Único de Saúde.
\end{abstract}

\footnotetext{
${ }^{1}$ Faculdade de Odontologia, Universidade Federal de Mato Grosso do Sul (UFMS) - Campo Grande (MS), Brasil.

¿Universidade Federal de Viçosa (UFV) - Viçosa (MG), Brasil.

${ }^{3}$ Curso de Fisioterapia, Universidade Federal de Mato Grosso do Sul (UFMS) - Campo Grande (MS), Brasil.

${ }^{4}$ Programa de Pós-graduação em Saúde e Desenvolvimento na Região Centro-Oeste, Universidade Federal de Mato Grosso do Sul (UFMS) - Campo Grande (MS), Brasil.

Trabalho realizado na Faculdade de Odontologia, Universidade Federal de Mato Grosso do Sul (UFMS) - Campo Grande (MS), Brasil.

Endereço para correspondência: Alessandro Diogo De-Carli - Faculdade de Odontologia, Universidade Federal de Mato Grosso do Sul (UFMS), Av. Costa e Silva s/n - Pioneiros - CEP: 79070-900 - Campo Grande (MS), Brasil - E-mail: alessandrodecarli@hotmail.com

Fonte de financiamento: nenhuma.

Conflito de interesses: nada a declarar.
}

Este é um artigo publicado em acesso aberto (Open Access) sob a licença Creative Commons Attribution, que permite uso, distribuição e reprodução em qualquer meio, sem restrições desde que o trabalho original seja corretamente citado. 


\begin{abstract}
Background: The traditional model of hegemonic and technicist health training limits the answers to the current demands of the Unified Health System (USH). To overcome these weaknesses, Teaching-Service-Community Integration (TSCl) and Active Methodologies (AM) are presented as strategies for reorienting vocational training. Objective: This study analyzed the perceptions of dentistry students of Federal University of Mato Grosso do Sul (UFMS), related to pedagogical practices in light of AM and TSCI for and in the USH. Method: It was a qualitative research, which was carried out between 2012 and 2013, with 73 students, who were enrolled and attending the Compulsory Internship in Collective Health Dentistry II (CICHD II). The invitation was made after the course end, when the grades had already been released. A script was used containing guiding questions, which dealt with students' opinions about: (1) the course; (2) the potentialities and weaknesses of the teaching-learning methodology used and the Health Units attended; And (3) the intention to, after graduation, work in the USH /Family Health Strategy. After the data collection, they were transcribed and, subsequently, the Collective Subject Discourse (CSD) was processed. Results: The TSCI, which was articulated to the AM, allowed students to connect theory and practice, integrated to the realities of USH. Conclusion: They noted the relevance of the permanent education in health and the difficulties/potentialities of using active methodologies integrated to the $\mathrm{TSCl}$ in the professional formation, pointing the UHS as a real possibility of work when they will be graduate.

Keywords: staff development; dental education; dental students; active teaching-learning methodologies; Unified Health System.
\end{abstract}

\section{INTRODUÇÃO}

No Brasil, o Sistema Único de Saúde (SUS) tem passado por contínuas transformações para reafirmar a saúde como direito universal. Nessa direção, a Atenção Primária à Saúde (APS) tem assumido um papel fundamental para a coordenação das Redes de Atenção à Saúde (RAS), visando singularizar e reordenar o sistema e buscando resultados mais eficientes, equitativos e de menor custo na garantia do acesso universal à saúde no país ${ }^{1}$.

A Estratégia Saúde da Família (ESF) veio fortalecer a APS como coordenadora do sistema, manejando situações adversas para alcançar a integralidade na resolução das demandas de saúde das comunidades ${ }^{2}$. Para tal, os profissionais precisam desenvolver competências e habilidades para além da epidemiologia e das clínicas tradicionais, como a capacidade de construir vínculos, a autonomização e a corresponsabilização na produção da saúde ${ }^{1}$.

Nessa perspectiva, destaca-se ainda a importância de organizar os processos formativos para as RAS e a APS, uma vez que nesta se espera a resolubilidade de cerca de $80 \%$ dos problemas de saúde da população. Portanto, é preciso avançar muito na realidade da APS no Brasil, pois “[...] tende, na prática, a reproduzir o modelo biomédico dominante, sendo necessários esforços continuados e sistemáticos para reformular esse tipo de prática e de saber"3 (p. 8). A formação dos profissionais de saúde é considerada um nó crítico, tendo em vista seu caráter hegemônico hospitalocêntrico e reducionista ${ }^{4}$, distanciando-se das demandas sociais e persistindo na formação dos profissionais de saúde com base em modelos conservadores e centrados em altas tecnologias 5 . De acordo com Campos ${ }^{3}$, não apenas os graduandos em saúde, mas também os profissionais que atuam nas equipes necessitam estar em educação permanente em saúde (EPS).

A partir disso, propõe-se a construção de caminhos para aproximar a formação de profissionais de saúde das necessidades da APS, recomendando a reorientação da formação, com o estímulo da atuação multiprofissional alicerçada em um novo modelo de ensino-aprendizagem centrado no aluno e na integração ensino-serviço-comunidade (IESC), capaz de equilibrar a excelência técnica e a relevância social' ${ }^{6}$.

As Diretrizes Curriculares Nacionais (DCNs) do curso de Odontologia preconizam a formação profissional para ações de prevenção, promoção, proteção e reabilitação, no âmbito individual e coletivo, assegurando práticas integradas, contínuas, em complexidade crescente e consonantes com o SUS. Ademais, estabelecem que o projeto pedagógico do curso deve ser orientado para a formação integral do estudante, articulando ensino, pesquisa e assistência, centrado no aluno, tendo o docente como facilitador do processo de ensino-aprendizagem ${ }^{7}$. Assim, novas abordagens pedagógicas vêm sendo construídas e implicam formar profissionais como sujeitos sociais e com competências e habilidades para lidar com situações complexas. As metodologias ativas (MAs) têm sido reconhecidas como importantes instrumentos de transformação da formação profissional por romper com processos massificadores, pautar-se no princípio da autonomia, que busca no sujeito a capacidade de autogovernar seu processo de formação, e possibilitar uma formação problematizadora e dialética, reconhecendo o diálogo como indispensável para desvelar a realidade ${ }^{8-10}$.

Nesse alinhamento, no âmbito da Odontologia, há que se considerar a IESC enquanto dispositivo potencializador do processo de mudanças na formação em saúde, o que pode ser obtido por reestruturação curricular e adequação do projeto pedagógico dos cursos. Para isso ocorrer, é necessário sedimentação de ações plurais para a construção da interface ensino-serviço, por meio da inclusão de cenários de práticas diversificados desde os períodos iniciais do curso, o que tem sido percebido como um movimento de diferenciação em nível de formação dos graduandos em relação às dimensões sociais e comunitárias e também ao conhecimento do SUS ${ }^{11-13}$.

Para que essa mudança seja realmente vivenciada, a abordagem de ensino-aprendizagem necessita incluir metodologias participativas, que estimulem o papel ativo dos estudantes ${ }^{11,14}, \mathrm{e}$ processos avaliativos processuais ${ }^{11} \mathrm{e}$ formativos. Isso ganha maior 
sustento quando estudantes de Odontologia reconhecem que as MAs de aprendizagem favorecem a capacidade de aprender de forma autônoma, desenvolvendo o pensamento crítico, com a finalidade de analisar soluções de problemas e refletir sobre elas ${ }^{15}$, que, no caso da vivência no SUS, são reais.

Diante dessas considerações, o objetivo deste estudo foi analisar as percepções dos estudantes de Odontologia acerca da vivência do processo de ensino-aprendizagem à luz de MAs na perspectiva da IESC no e para o SUS. Ressalta-se que, embora escassos os estudos sobre a percepção dos graduandos em Odontologia, nos cenários de prática do SUS, podem contribuir para qualificar a formação desses profissionais em consonância com a realidade e as demandas das populações, incentivando estudantes a trabalhar no SUS e contribuindo para seu fortalecimento ${ }^{16}$.

\section{MÉTODO}

A abordagem qualitativa foi eleita para este estudo, pois, enquanto campo transdisciplinar, adota multiparadigmas de análise e multimétodos de investigação para o encontro de sentidos e interpretação de significados. Isso implica "[...] uma partilha densa com pessoas, fatos e locais que constituem objetos de pesquisa, para extrair desse convívio os significados visíveis e latentes"17 (p. 221).

Este estudo foi aprovado pelo Comitê de Ética em Pesquisa da UFMS sob n ${ }^{\circ}$ CAAE: 03578312.9.0000.0021 e Parecer n 48804.

\section{Participantes e cenários de ensino-aprendizagem}

Foram incluídos neste estudo todos os acadêmicos da Faculdade de Odontologia (Faodo), da Universidade Federal de Mato Grosso do Sul (UFMS), que estavam matriculados e finalizaram a disciplina de Estágio Obrigatório de Odontologia em Saúde Coletiva II (EOOSC II), no período de $2012(\mathrm{n}=40)$ a 2013 ( $n=49$ ). Desse total de 89 sujeitos, 73 concordaram em participar da pesquisa. O convite foi feito após o encerramento da disciplina, quando as notas já haviam sido lançadas.

A escolha dos acadêmicos como participantes deste estudo ocorreu por considerar sua implicação para o processo de ensino-aprendizagem, tendo em vista que a disciplina em questão possibilitava a primeira experiência extramuros dos estudantes do $3^{\circ}$ semestre do curso de graduação em Odontologia - o primeiro contato, do ponto de vista acadêmico, com o SUS. Além disso, as MAs foram adotadas, a partir de 2012, pela disciplina, que até então fazia uso das metodologias de ensino-aprendizagem tradicionais, centradas no professor. Necessitava-se, então, de uma devolutiva, sob a ótica dos estudantes, a respeito das transformações que estavam ocorrendo na disciplina e no processo de ensino-aprendizagem.

Os cenários de práticas foram as RAS do município de Campo Grande (MS), com ênfase na APS (Unidades Básicas de Saúde
- UBS - e Unidades Básicas de Saúde da Família - UBSF), além de vivências no Centro de Especialidades Odontológicas (CEO), no Centro de Especialidades Médicas (CEM), nos Centros de Atenção Psicossocial Álcool e Drogas e Infantil (CAPS ad e CAPS i), nas Policlínicas Odontológicas, na Unidade de Pronto Atendimento (UPA), no Hospital Universitário da UFMS e no Conselho Municipal de Saúde.

Em 2012, a introdução das MAs ocorreu assistematicamente, e a disciplina foi construída e reconstruída a partir de ações, diálogos, feedbacks e reflexões coletivas, a fim de atingir os objetivos de aprendizagem e o desenvolvimento de competências necessárias à formação profissional dos estudantes, conforme o projeto pedagógico do curso e as DCNs 7 . Em 2013, o processo foi sistematizado, e a proposta do uso de MAs e da IESC foi problematizada com os alunos, desde o primeiro dia de aula. Apesar de a maior parte da carga horária ocorrer extramuros, houve encontros em sala de aula, principalmente em seminários, em que se problematizavam as vivências dos cenários de práticas em consonância com os objetivos e as competências previstas no planejamento da disciplina.

Inicialmente, propôs-se a reflexão sobre as situações vivenciadas extramuros, trazidas e selecionadas pelos estudantes como relevantes para a aprendizagem. Foram realizadas discussões coletivas, possibilitando que os conhecimentos prévios dos alunos fossem explicitados. Tal ação estava pautada na aprendizagem significativa, que busca o estabelecimento de associações entre os elementos novos e aqueles já presentes na estrutura cognitiva dos alunos, o que permite vislumbrar os hiatos de conhecimento e as novas necessidades para a solução de problemas.

$\mathrm{Na}$ etapa seguinte, os alunos foram estimulados a distinguir os pontos essenciais a serem abordados para compreensão do problema e instigados a pesquisar as possíveis soluções e teorizar sobre elas. Ao retornarem a campo e confrontarem suas hipóteses de solução, muitas vezes verificavam as multidimensões do problema e novas problematizações ocorriam. Enfatiza-se o importante papel do docente como facilitador \mediador nesse contínuo processo de ensino-aprendizagem, potencializado nas MAs. Nesse sentido, a relação docente-discente configura-se como duas faces de uma mesma moeda, em que, inevitavelmente, esses atores compartilham cada vez mais parcelas de responsabilidade e comprometimento ${ }^{9,18}$.

Em se tratando de MAs, inovações no campo da avaliação do processo de ensino-aprendizagem também foram propostas na disciplina, pois se buscou ultrapassar a pura verificação de conteúdos memorizados ${ }^{18}$. Dessa forma, optou-se pela avaliação formativa ${ }^{19}$, cuja finalidade não prioriza somente a performance cognitiva, mas todo o caminhar do aluno durante a disciplina, sua criticidade, sua autonomia e sua evolução enquanto ator social aprendente, ensinante e, possivelmente, transformador da realidade. 
Entre as atividades realizadas na disciplina foram pontuados os seminários, os registros, os relatórios, as pesquisas, a síntese de diálogos e a autoavaliação permanente, visando estimular o desenvolvimento de habilidades e atitudes como autonomia, iniciativa, criatividade, colaboração e comunicação. No seminário final, os alunos puderam escolher uma modalidade de apresentação (dramatizações, música, dinâmicas ou mesmo uma exposição dialogada).

\section{Coleta e análise dos dados}

Dois professores da disciplina elaboraram um roteiro de entrevista semiestruturada com questões norteadoras sobre a visão dos estudantes acerca do estágio extramuros, as potencialidades e as fragilidades da metodologia de ensino-aprendizagem utilizada e das unidades de saúde frequentadas durante o EOOSC II, assim como a intenção de, após a formatura, trabalhar no SUS/ESF.

Desse modo, foram obtidas 73 entrevistas que foram gravadas em arquivos de áudio, caracterizando amostragem por exaustão ${ }^{20}$, considerando que foi ouvida a totalidade dos participantes que estavam matriculados na disciplina e que aceitaram participar da pesquisa. Os dados foram coletados em sala específica para essa finalidade.

Após a coleta, os dados foram transcritos, na íntegra, por três pesquisadores e submetidos às leituras flutuantes e, posteriormente, exaustivas/profundas.

Para análise dos dados transcritos, optou-se pelo discurso do sujeito coletivo (DSC), que representa uma visão consensual da realidade entre os membros de um grupo, conformando depoimentos coletivos obtidos de extratos de diversos depoimentos individuais, que se expressam como fato empírico, pela "boca" de um único sujeito do discurso ${ }^{21,22}$. Assim, constitui uma forma de resgate e apresentação das representações sociais, as quais se aproximam “[...] das opiniões como elas de fato são praticadas por coletividades de atores sociais", aqui entendidos como indivíduo/coletivo e sujeito falando/falado ${ }^{22}$ (p. 503).

O DSC explicita um ser ou uma entidade coletiva, opinante como sujeito do discurso, emitido na primeira pessoa do singular $^{18}$, alicerçado pela teoria das representações sociais ${ }^{23}$.

No DSC, o pensamento (matéria significante) pode ser percebido como uma variável qualitativa e quantitativa. Este estudo foi, assim, delineado sob a vertente qualitativa do DSC ${ }^{21}$, por meio da seleção de Expressões-Chave - EC (trechos mais significativos das respostas), que estão contidas nas Ideias Centrais - IC (síntese do conteúdo discursivo das EC), a partir das quais foi obtido o DSC.

A etapa de análise dos dados foi realizada por dois pesquisadores e validada por um terceiro, a fim de que a confiabilidade e a fidedignidade fossem contempladas.

\section{RESULTADOS E DISCUSSÃO}

Conhecendo o SUS na prática e reconhecendo a importância da Educação Permanente em Saúde (EPS) já na graduação

No Quadro 1, ao serem questionados sobre a visão geral da disciplina, os acadêmicos demonstraram a importância de conhecer a realidade do SUS, principalmente na APS e na ESF. Além disso, evidenciou-se que realizaram as conexões necessárias entre teoria e prática, nas diferentes vivências e atividades intra e extramuros, especialmente nos seminários, cujos temas problematizados foram: Políticas Públicas de Saúde; Reforma Sanitária; Princípios do SUS; Integralidade; Política Nacional de Saúde Bucal. Reconheceram também que a IESC, articulada com as MAs, contribuiu para que compreendessem a importância da EPS em contextos complexos das RAS e evidenciassem a necessidade de continuar apreendendo para transformar a realidade e exercer sua cidadania.

Tal conexão direta e permanente entre teoria e prática facilita o entendimento dos estudantes. Para tal, docentes necessitam ser capacitados nesse novo processo com o objetivo de horizontalizar a relação com os alunos, por meio do contato prolongado e da formação de vínculos, estimulando a reflexão crítica sobre a realidade de sua atuação profissional ${ }^{24}$.

Entendendo a EPS como o caminho para os novos modos de educar no e para o SUS ${ }^{25}$ e as MAs como provocadoras de reflexão sobre o processo de trabalho e necessidades de aprendizagem (no trabalhador e no acadêmico), além de considerar a realidade de seu território, permite-se não apenas (re)formar

Quadro 1. Ideia Central: a disciplina propiciou o conhecimento da realidade e das noções de educação permanente em saúde no SUS DSC

"Eu acho que a disciplina fez com que eu conhecesse melhor o sistema público de saúde e suas políticas, principalmente a ESF [...] a gente viu a realidade de seu funcionamento, né?! Colaborou para a minha formação para ficar atento [...] o professor sempre falava que a gente tem que ser capaz, preparado para trabalhar no SUS. Se for na ESF, então, nem se fala, pois vou trabalhar o dia inteiro com uma mesma população, num mesmo bairro. Eu vi na teoria, nos seminários como funciona o SUS e a ESF, e depois comprovei na prática seu funcionamento. Aqui neste estágio aprendi que o estudo é pra sempre, constante. Não basta estudar para passar de ano. Tenho que estudar para saber lidar com o trabalho lá fora, depois da formatura [...] Estudar é importante sempre. Vi que na Saúde da Família principalmente, problemas diferentes surgem a todo momento, então depois que estiver trabalhando, [...] continuarei tendo que estudar, até pra resolvermos estes problemas que vão surgir. A necessidade de estudar depois de formado não vai ser pra passar de ano, né?! Vai ser pra continuar nossa qualificação profissional e muito em função do que o serviço público de saúde 'pedir' [...] isso pra quem for trabalhar no SUS. Vi que tanto no CEO quanto nas UBSFs as situações do cotidiano vão surgindo, e você tem que estar preparado para resolver...se você não sabe resolver na hora, terá que buscar a saída...na verdade, pra isto é que devemos estar estudando permanentemente, né? [...] Aquele esquema de construção do conhecimento, que o professor falou em sala..... 
os profissionais ${ }^{26}$, mas, principalmente, articular clínica, gestão e pedagogia. Isso toma dimensão crítica quando se aceita que a "[...] produção do cuidado em saúde e sua micropolítica são constituídas de práticas pedagógicas, e não só de ações tecnológicas típicas da construção de atos de saúde"27 (p. 172).

As equipes precisam assumir como parte do seu processo de trabalho o protagonismo no ensino em saúde “[...] por meio de uma compreensão de educação permanente de si mesma e dos educandos que atravessarem sua história"28 (p. 582), uma vez que compete ao SUS, de acordo com o art. 200 da Constituição Federal, “[...] ordenar a formação de recursos humanos na área da saúde"29.

Isso ganha fortalecimento quando, como evidenciado em estudo prévio, na percepção dos próprios estudantes, há o sentimento de que os estágios contribuem com o desenvolvimento de processos/estratégias inovadoras para: o serviço, a EPS, as atividades de promoção, a prevenção e a educação em saúde. Esses processos podem ser potencializadores do trabalho dos profissionais do serviço e de uma formação, em nível de graduação, diferenciada, que retroalimentará a força de trabalho no SUS, com a inserção de futuros profissionais na rede de atenção à saúde ${ }^{12}$.

\section{Reconhecendo a complexidade do fazer em saúde}

No Quadro 2, os alunos identificaram ruídos e entraves que dificultavam o funcionamento adequado das RAS no SUS, não relacionados à falta de infraestrutura e equipamentos, mas aos processos de trabalho, à gestão e à falta de preparo dos profissionais para lidarem com as demandas cotidianas do serviço.

É necessário construir uma rede permanente de conversações e trabalhar pela transição tecnológica no setor da saúde, que resulte na hegemonia do trabalho vivo em ato, das tecnologias leves, e que tenha efetivamente a APS como organizadora da RAS $^{27,28}$. E a EPS pode ser a operacionalização dessa rede de conversações, posto que se diferencia da forma tradicional de aprender e possui enfoque nos problemas cotidianos das práticas das equipes de saúde, objetivando transformações práticas, técnicas e sociais ${ }^{26}$.

Quadro 2. Ideia Central: o trabalho em saúde como um processo complexo

\section{DSC}

"De maneira geral, a infraestrutura é boa. O que falta é profissional preparado para atuar no SUS. Falta comprometimento dos profissionais [...] Além disso, mesmo com a 'infra' boa, parece que a rede do sistema não funciona direito. Deve faltar administração para isso acontecer tanto [...] Nas atividades extramuros nas unidades de saúde, deu pra perceber que geralmente ofuncionamento é muito bom, com um certo planejamento [...] mas parece que tem alguma coisa errada ali, tem alguma coisa que falha. Não sei se é a gestão, ou o que [...] falta organização de alguma coisa [...] se a gestão organizasse melhor, a rede de serviços funcionaria...."
As pedagogias problematizadoras possuem amplitude para a formação dessas redes de pessoas. O potencial da EPS em construir espaços coletivos para a reflexão e avaliação de sentido dos atos produzidos no cotidiano, que levam em conta “[...] problemas reais, pessoas reais e equipes reais" (p. 167) precisa se efetivar, preparando permanentemente os profissionais e os estudantes no e para o SUS.

\section{Reconhecendo a novidade das metodologias ativas, aprendendo e avaliando de um jeito diferente}

No Quadro 3, os alunos apontaram as fragilidades e os pontos fortes da proposta pedagógica em articular as MAs com os cenários de prática, além de constar a diferença com as demais disciplinas, o posicionamento do professor e do

Quadro 3. Ideia Central: dificuldades e potencialidades com metodologias ativas de aprendizagem e relação professor-estudante, inclusive na avaliação

\section{DSC}

"O tipo de metodologia usado dificultou o aprendizado porque eu não sou acostumado a construir o conhecimento junto com o professor, mas é uma maneira de formar um profissional mais crítico e reflexivo [...] A ida aos postos de saúde mostrou a realidade que me espera lá fora depois que a gente se formar e as discussões em grupo foram os pontos positivos da disciplina. Mas isso de construir o conhecimento é difícil, pois nós não somos assim [...] queremos tudo pronto, mais cômodo né [...] agora entendo porque no início do semestre o professor fez com que estudasse as coisas do pensamento crítico-reflexivo, tem até o autor que foi indicado [...] não lembro [...] mas mesmo estudando tudo isso e discutindo na sala de aula, é difícil para a gente, principalmente no início [...] seria muito mais fácil se o professor viesse com os slides prontos e repassasse. A construção do conhecimento que essa disciplina propôs foi o que mais se diferenciou das outras disciplinas do curso até agora né, a gente fazendo e não só o professor [...] Apesar de que ele complementava as explicações e tirava dúvidas, tanto nos seminários como nas atividades extramuros. Essa técnica faz com que o aluno reflita mais sobre os assuntos e não reproduza simplesmente o conhecimento dos outros, formando sua própria opinião [...] A abordagem dessa disciplina foi mais humanizada e menos formal, como as outras não são [...] o diálogo e a relação mais igualitária com o professor fez com que a gente tivesse a oportunidade de contribuir para a formação do conhecimento [...] Encontrei um professor aberto ao diálogo, não tivemos medo de opinar e de me expressar. Assim dá pra refletir mais, embora seja difícil pensar [...] Sempre fiz as discussões em forma de diálogos, o que é importante. Isso favorece o aprendizado, pois passo de passivo para ativo [...] mas o desempenho depende da individualidade de cada um, do compromisso de realizar os deveres a ele destinados. O que foi diferente das outras disciplinas, até agora [...] nas discussões os alunos puderam participar expondo diferentes pontos de vista e até a minha opinião mesmo, nada foi imposto como verdade absoluta. A forma de avaliar foi justa, mas estranha... Nunca fui avaliado constantemente, sempre, em toda aula, e o professor justificava a nota na hora, mostrando aquilo que estava bom e aquilo que podia ser melhor. Então, a avaliação foi diferente, feita em todos os encontros, logo após as discussões. Isso é bom, mas dá um medo, por que é o aqui e agora, no ato. Mas o importante é que sempre os pontos positivos dos alunos e dos seminários foram ditos, não somente os negativos. Isso foi diferente". 
aluno na metodologia utilizada, bem como a possibilidade de diálogo e expressão das próprias ideias, sendo constante o desafio a pensar.

Reconhece-se a dificuldade de lidar com esse novo jeito de estudar, aprender e construir o conhecimento com o professor, já que o habitual é receber conteúdos prontos; inclusive, alguns admitiram o desenvolvimento do pensamento crítico-reflexivo.

A educação tradicional, pautada nos pilares "escute, leia, decore e repita" ${ }^{30}$, considera o docente como o principal interlocutor, portador do conhecimento. Assim, a comunicação que se estabelece é puramente transmissiva, hierárquica e unidirecional, e os discentes tornam-se receptores passivos e exímios memorizadores ${ }^{9,21}$. Tal educação "bancária" ${ }^{11}$ preconiza a formação da consciência ingênua, em que os alunos são exercitados a memorizar acriticamente os conteúdos, pelo arquivamento dos depósitos que lhe são feitos, impedindo que desenvolvam a consciência crítica que os insere no mundo como transformadores dele. Ao contrário, uma educação libertadora deve ser uma prática capaz de lançar uma nova lógica na compreensão do mundo: crítica, comunicativa, criativa, responsável e comprometida com sua transformação ${ }^{31}$. Nessa direção, as MAs, pautadas nos pilares aprender a aprender, a fazer, a ser e a conviver ${ }^{32}$, fundamentam-se no aumento da capacidade dos discentes em participar como agentes de transformação social, descondicionando-os da atitude de meros receptores de conteúdos e os estimulando a buscar sua autonomia e seu autogerenciamento na construção de conhecimentos relevantes à sua formação profissional.

Vale registrar que os serviços de saúde são os locais em que se desenvolvem os modelos assistenciais, e, quando problematizados, podem produzir reflexões e construção de novos modos de olhar os sujeitos que necessitam de cuidado, transformando a atuação profissional e esses modelos ${ }^{21}$. Professores, equipes da APS e demais níveis de complexidade do SUS (RAS) precisam aprender a acolher os discentes, tornando as práticas em oportunidades únicas de perceber a dinamicidade da vida, com saúde, doença, nascimento, morte e todas as necessidades que dela surgem ${ }^{33}$.

O papel do professor nas MAs é o de provocar o pensamento dos alunos, gerando desequilíbrios, a fim de promover novos conhecimentos significativos $^{34}$. Nessa lógica, as MAs têm a potência de formar profissionais sujeitos da própria história, capacitando-os para intervir em contextos de incertezas e complexidades, respeitando sua bagagem cultural e seus saberes construídos, na prática, em sua vida ${ }^{21}$.

O educar pela pesquisa promove a reconstrução do conhecimento capaz de superar a educação bancária (transmissão), e a escola precisa se adequar a essa era tecnológica e promover nos sujeitos aprendizados capazes de gerar autonomia intelectual e consciência crítica, que provoquem questionamentos e intervenções na realidade ${ }^{35}$. Por isso, é necessário um reposicionamento da função de professor, que precisa compreender que "não há docência

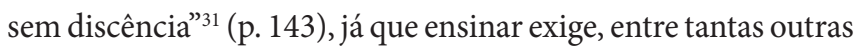

coisas, respeito aos saberes dos educandos, criticidade, estética e ética, reflexão crítica sobre a prática, bom senso, humildade, alegria e esperança, competência profissional e desejo do bem aos educandos ${ }^{31}$.

O preparo e o rigor científico do professor precisam coincidir com sua retidão ética, e o aluno deve compreender o compasso entre ambos. É preciso ousar para desenvolver a curiosidade no educando e para que, "pela força criadora de aprender"31 (p. 143), seja capaz de intervir no mundo e transformá-lo.

Outra inovação na prática da disciplina pode ser vivenciada pelos alunos ao se optar pela avaliação formativa, causando estranhamento, receio e diferença. As DCNs sugerem a avaliação como uma atividade permanente, que não deve ser dissociada da dinâmica de ensino-aprendizagem, capaz de gerar oportunidades de ação-reflexão-ação. Portanto, deve permitir a identificação não somente das aprendizagens desenvolvidas, mas também propiciar um diagnóstico de problemas e dificuldades apresentadas pelos estudantes na produção de conhecimentos, de habilidades e de atitudes fundamentais para sua formação profissional. Feedbacks permanentes e reflexão crítica sobre o processo de ensino-aprendizagem em ato podem permitir aos estudantes vislumbrarem suas reais dificuldades e fragilidades, além de seus pontos fortes. Podem ainda alertar os docentes a revisitar suas práticas pedagógicas, estimulando a buscar correção de rotas, melhorias e avanços no desenvolvimento de competências ${ }^{9,21,36}$.

\section{O SUS como possível cenário de trabalho}

Integrar as MAs vivenciadas na disciplina aos cenários reais de prática possibilitou aos estudantes vislumbrarem-se no mundo do trabalho (Quadro 4), analisarem alguns "prós e contras" do SUS e compreenderem que não basta saber técnico-científico, mas que é necessária uma visão mais crítico-reflexiva acerca da realidade do sistema, percebendo a ESF como uma porta de acesso para a Odontologia.

Quadro 4. Ideia Central: O SUS como possibilidade de carreira ou como necessidade

\section{DSC}

"Foi importante para conhecer os prós e contras do Sistema Único de Saúde e para ajudar na minha formação né...despertou na gente aquele negócio de ser crítico e reflexivo e não somente técnico, científico, ampliou minha visão sobre a profissão e sobre o mercado de trabalho também, por que hoje todo mundo se forma e quer trabalhar na Saúde da Família...têm colegas que já saíram da faculdade aprovados em concurso de Saúde da Família. Eu gostaria de trabalhar no SUS sim. Não pela necessidade, mas pela identificação com seus princípios. Eu sei que ganhar dinheiro é importante..., mas também tenho que responder às necessidades sociais da população, já que estudo em uma universidade pública, sem falar que hoje em dia ganha-se dinheiro também trabalhando na saúde pública. Necessito de um emprego e salário fixo. É uma questão econômica mesmo...hoje em dia, temos que pensar bastante no salário fixo e na segurança do serviço público". 
Seja na graduação, seja na pós-graduação, todos os profissionais de saúde precisam (re)aprender a respeito da saúde no Brasil, conhecendo as necessidades de saúde da população e também os novos modos de fazer saúde propostos no SUS. Para tanto, é fundamental que professores e preceptores em saúde sejam (trans)formados para conhecer essas necessidades ${ }^{36}$.

Os acadêmicos reconheceram como valiosa a ida às unidades de saúde, o território vivo, ficando divididos quanto ao desejo de trabalhar no SUS: alguns revelaram a identificação com os princípios, enquanto outros admitiram que o deverão fazer por questões financeiras.

O resgate da IESC na vida acadêmica precisa ser um alvo para as instituições de ensino superior, para que mudanças sejam disparadas no processo de formação em saúde. Isso implica o (re)encontro entre ensino e serviço, a criação de um espaço permanente de reflexão sobre os processos de trabalho e os de ensino-aprendizagem. Nesse sentido, é fundamental que sejam identificados as potencialidades e os desafios na formação para o SUS, com o objetivo de transformar tanto o ensino quanto o serviço ${ }^{37}$. Faz-se necessário que parcerias entre a universidade e a gestão do SUS se estabeleçam a fim de que a formação efetivamente se volte para a implementação dos princípios e das diretrizes constitucionais do SUS, oportunizando experiências de caráter multiprofissional e interdisciplinar e operacionalizando as DCNs. Necessário e oportuno é “[...] apostar na possibilidade de construção do novo, investir no estabelecimento de relações horizontalizadas, onde todo o produto e frutos são compartilhados" ${ }^{37}$ (p. 26).

As mudanças no modelo de atenção à saúde implicam muitas transformações, inclusive na prática profissional, que está vinculada às transformações no pensamento e ação dos profissionais da área de saúde, o que torna iminentes as modificações nos processos formativos. Nesse direcionamento, tem-se que considerar a pertinência e a viabilização da interprofissionalidade e da IESC, visando à aproximação dos estudantes com a realidade social e sanitária da população e com o processo de trabalho dos serviços de saúde, buscando expansão do entendimento do processo de saúde-doença e da assistência integral na produção do cuidado ${ }^{13}$.
Considerando os resultados deste estudo, destaca-se que as iniciativas que estabeleçam diálogo entre as MAs, a avaliação formativa e a IESC devem ser estimuladas desde o início da graduação, pois têm a potência de induzir mudanças no ensinar, aprender e fazer em saúde, as quais são necessárias (e até certo ponto essenciais) para que se avance em termos de políticas públicas de ensino e de saúde.

\section{CONSIDERAÇÕES FINAIS}

Os estudantes de Odontologia sujeitos deste estudo identificaram a importância de conhecerem a realidade do SUS, a relevância da EPS e as dificuldades/potencialidades da utilização de MAs integradas à IESC na formação profissional, reconhecendo as diferenças na condução da disciplina e na relação docente-discente em comparação a outras disciplinas cursadas até então, além de apontarem o SUS como possibilidade de trabalho.

Nessa perspectiva, a adoção do SUS como cenário diversificado de ensino-aprendizagem e das MAs/avaliação formativa como práticas pedagógicas cotidianas apresenta-se enquanto iniciativa potente para estimular o caráter transformador da formação, visando ao agir crítico-reflexivo que possibilite o fazer em saúde em consonância com demandas reais. No campo da formação profissional em Odontologia, em nível de graduação, isso toma dimensão decisiva na reorientação paradigmática, o que implica a transposição de um escopo de práticas de ensino-aprendizagem centradas no docente, tecnicista, compartimentalizado e desconexo da realidade, para um fluxo de desenvolvimento de competências e habilidades que valoriza o estudante, as ações em saúde em sentido amplo e o contexto em que os cidadãos (estudantes, docentes, profissionais de saúde e comunidade) constroem seu viver.

Dificuldades com a construção do conhecimento e o desenvolvimento do pensamento crítico-reflexivo foram evidenciadas quanto à aplicação das MAs. Isso denota a necessidade, no que se refere à atuação docente, de haver constância em direção ao planejamento, avaliação (da disciplina) e desenvolvimento do hábito da escuta dos discentes, que são capazes de apresentar indicadores que podem qualificar e otimizar o processo de ensino-aprendizagem.

\section{REFERÊNCIAS}

1. Brasil. Ministério da Saúde. Projeto SB Brasil 2010: condições de saúde bucal da população brasileira 2009-2010: resultados principais. Brasília: Ministério da Saúde; 2011.

2. Brasil. Ministério da Saúde. Secretaria de Gestão Participativa. Saúde da Família: panorama, avaliação e desafios. Brasília: Ministério da Saúde; 2005.

3. Campos GWS. Papel da rede de atenção básica em saúde na formação médica: diretrizes. Cad ABEM. 2007;3:6-10.

4. Almeida NM Fo. Contextos, impasses e desafios na formação de trabalhadores em Saúde Coletiva no Brasil. Cien Saude Colet. 2013;18(6):1677-82. http:// dx.doi.org/10.1590/S1413-81232013000600019. PMid:23752534.

5. Ceccim RB, Feuerwerker LC. Mudança na graduação das profissões de saúde sob o eixo da integralidade. Cad Saude Publica. 2004;20(5):1400-10. http://dx.doi.org/10.1590/S0102-311X2004000500036. PMid:15486685.

6. Campos FE, Ferreira JR, Feuerwerker L, Sena RR, Campos JJB, Cordeiro $\mathrm{H}$, et al. Caminhos para aproximar a formação de profissionais de saúde das necessidades da atenção básica. Rev Bras Educ Med. 2001;25(2):53-9.

7. Brasil. Conselho Nacional de Educação. Câmara de Educação Superior. Resolução CNE/CES 3, de 19 de fevereiro de 2002. Institui as Diretrizes Curriculares Nacionais do Curso de Graduação em Odontologia. Diário Oficial da União [Internet], Brasília, 4 de março de 2002 [citado em 20016 Fev 1]. Disponível em: http//:portal.mec.gov.br 
8. Cotta RMM, Costa GD, Mendonça ET. Portfólio reflexivo: uma proposta de ensino e aprendizagem orientada por competências. Cien Saude Colet. 2013;18(6):1847-56. http://dx.doi.org/10.1590/S1413-81232013000600035.

9. Noguero FL. Metodología participativa en la enseñanza univeristaria. 3. ed. Madrid: Narcea S.A. de Ediciones; 2007. 176 p.

10. Gomes AP, Arcuri MB, Cristel EC, Ribeiro RM, Souza LMBM, SiqueiraBatista R. Avaliação no ensino médico: o papel do portfólio nos currículos baseados em metodologias ativas. Rev Bras Educ Med. 2010;34(3):390-6. http://dx.doi.org/10.1590/S0100-55022010000300008.

11. Souza AL, Carcereri DL. Qualitative study of the teaching-service integration in an undergraduate Dentistry course. Interface. 2011;15(39):1071-84. http://dx.doi.org/10.1590/S1414-32832011005000025.

12. Pessoa TRRF, Castro RD, Freitas CHSM, Reichert APS, Forte FDS. Formação em Odontologia e os estágios supervisionados em serviços públicos de saúde: percepções e vivências de estudantes. Rev ABENO. 2018;18(2):14455. http://dx.doi.org/10.30979/rev.abeno.v18i2.477.

13. Madruga LMS, Ribeiro KSQS, Freitas CHSM, Pérez IAB, Pessoa TRRF, Brito GEG. The PET-Family Health and the education of health professionals: students' perspectives. Interface. 2015;19(Supl 1):805-16. http://dx.doi. org/10.1590/1807-57622014.0161.

14. Vendruscolo C, Prado ML, Kleba ME. Integração Ensino-Serviço no âmbito do Programa Nacional de Reorientação da Formação Profissional em Saúde. Cien Saude Colet. 2016;21(9):2949-60. http://dx.doi.org/10.1590/141381232015219.12742015. PMid:27653080.

15. Ferraz AML Jr, Miranda NR, Assunção R, Silva SA, Oliveira FAM, Oliveira RG. Percepção de estudantes de Odontologia sobre metodologias ativas no processo de ensino-aprendizagem. Rev ABENO. 2016;16(3):66-77. http:// dx.doi.org/10.30979/rev.abeno.v16i3.272.

16. Leme PAT, Pereira AC, Meneghim MC, Mialhe FL. Perspectivas de graduandos em odontologia acerca das experiências na atenção básica para sua formação em saúde. Cien Saude Colet. 2015;20(4):1255-65. http:// dx.doi.org/10.1590/1413-81232015204.00812014. PMid:25923636.

17. Minayo MC. Análise qualitativa: teoria, passos e fidedignidade. Cien Saude Colet. 2012;17(3):621-6. http://dx.doi.org/10.1590/S1413-81232012000300007. PMid:22450402.

18. Mitre SM, Siqueira-Batista R, Girardi-de-Mendonça JM, Morais-Pinto NM, Meirelles CAB, Pinto-Porto C, et al. Metodologias ativas de ensinoaprendizagem na formação dos profissionais de saúde: debates atuais. Cien Saude Colet. 2008;13(2 Supl 2):2133-44. http://dx.doi.org/10.1590/ S1413-81232008000900018.

19. Perrenoud $\mathrm{P}$. Avaliação: da excelência à regulação das aprendizagens entre duas lógicas. Porto Alegre: Artes Médicas; 1999.

20. Fontanella BJ, Ricas J, Turato ER. Amostragem por saturação em pesquisas qualitativas em saúde: contribuições teóricas. Cad Saude Publica. 2008;24(1):17-27. http://dx.doi.org/10.1590/S0102-311X2008000100003. PMid:18209831.

21. Lefèvre F, Lefèvre AMC. O discurso do sujeito coletivo: um novo enfoque em pesquisa qualitativa (desdobramentos). Caxias do Sul: EDUSC; 2003.

22. Lefèvre F, Lefèvre AMC. Discurso do sujeito coletivo: representações sociais e intervenções comunicativas. Texto Contexto Enferm. 2014;23(2):502-7. http://dx.doi.org/10.1590/0104-07072014000000014.

23. Moscovici S. Representações sociais: investigações em psicologia social. 11. ed. Petrópolis: Vozes; 2015. 404 p.
24. Ferreira RC, Fiorini VML, Crivelaro E. Formação profissional no SUS: o papel da Atenção Básica em Saúde na perspectiva docente. Rev Bras Educ Med. 2010;34(2):207-15. http://dx.doi.org/10.1590/S0100-55022010000200004.

25. Brasil. Ministério da Saúde. Secretaria de Gestão do Trabalho e da Educação na Saúde. Departamento de Gestão da Educação na Saúde. Política de educação e desenvolvimento para o SUS: caminhos para a educação permanente em saúde: pólos de educação permanente em saúde. Brasília: Ministério da Saúde; 2004. 68 p.

26. Ceccim RB. Educação permanente em saúde: desafio ambicioso e necessário. Interface. 2005;9(16):161-77. http://dx.doi.org/10.1590/S141432832005000100013 .

27. Merhy EE. O desafio que a educação permanente tem em si: a pedagogia da implicação. Interface. 2005;9(16):161-77.

28. Barreto VHL, Monteiro ROS, Magalhães GSG, Almeida RCC, Souza LN. Papel do preceptor da Atenção Primária em Saúde na Formação da Graduação e Pós-graduação da Universidade Federal de Pernambuco: um termo de referência. Rev Bras Educ Med. 2011;35(4):578-83. http://dx.doi. org/10.1590/S0100-55022011000400019.

29. Brasil. Constituição da República Federativa do Brasil de 1988. Diário Oficial da União [Internet], Brasília, 5 de outubro de 1988.

30. Dreher SAS, Beltrami K, Kuster SMGS, Behrens MA. Os paradigmas e seus reflexos na educação. In: Anais do VII Congresso Nacional de Educação (EDUCERE) [Internet]; 2007; Curitiba. Curitiba: PUCPR; 2007 [citado em 2016 fev 3]. Disponível em: http://www.pucpr.br/eventos/educere/ educere2007/anaisEvento/arquivos/CI-174-05.pdf

31. Freire P. Pedagogia da autonomia: saberes necessários à prática educativa. 43. ed. São Paulo: Paz e Terra; 2011. 48 p.

32. Delors J, Al-Mufti I, Amagi I, Carneiro R, Chung F, Geremek B, et al. Educação um tesouro a descobrir: relatório para a UNESCO da Comissão Internacional sobre Educação para o século XXI. São Paulo: CORTEZ; 1998.

33. Costa JRB, Romano VF, Costa RR, Vitorino RR, Alves LA, Gomes AP, et al Médica na estratégia de saúde da família: percepções discentes. Rev Bras Educ Med. 2012;36(3):387-400. http://dx.doi.org/10.1590/S010055022012000500014 .

34. Cyrino EG, Toralles-Pereira ML. Trabalhando com estratégias de ensinoaprendizado por descoberta na área da saúde: a problematização e a aprendizagem baseada em problemas. Cad Saude Publica. 2004;20(3):780-8. http://dx.doi.org/10.1590/S0102-311X2004000300015. PMid:15263989.

35. Freiberger RM, Berbel NAN. A importância da pesquisa como princípio educativo na atuação pedagógica de professores de educação infantil e ensino fundamental. Cad Educ. 2010;37:207-45.

36. Cotta RMM, Silva LS, Lopes LL, Gomes KO, Cotta FM, Lugarinho R, et al. Construção de portfólios coletivos em currículos tradicionais: uma proposta inovadora de ensino-aprendizagem. Cien Saude Colet. 2012;17(3):787-96. http://dx.doi.org/10.1590/S1413-81232012000300026. PMid:22450421.

37. Correia ADMS. Renascendo das cinzas: o resgate do sonho de ser educadora [trabalho de conclusão de curso]. São Paulo: Instituto Sírio-Libanês de Ensino e Pesquisa; 2014. 